\title{
ARTICLES
}

\section{Corrigendum: An empirical examination of echo chambers in US climate policy networks}

Lorien Jasny, Joseph Waggle and Dana R. Fisher

Nature Climate Change 5, 782-786 (2015); published online 25 May 2015; corrected after print 1 October 2015.

In the version of this Article originally published, the colouration and detail in Fig. 2 were incorrect. The corrected Fig. 2 is shown below.

Representative Markey (D-MA)
16 actors, 90 ties, 82 transitive triads

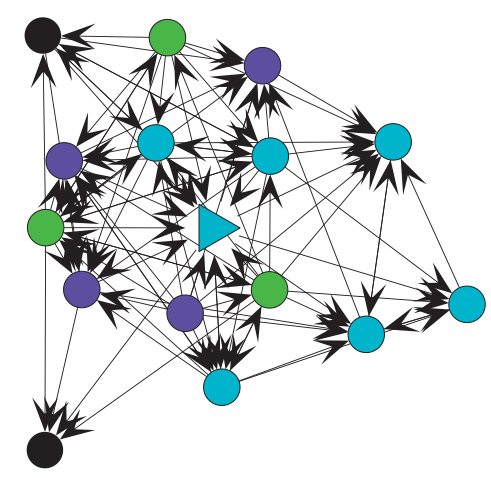

Representative Inhofe (R-OK)

4 actors, 4 ties, 1 transitive triad

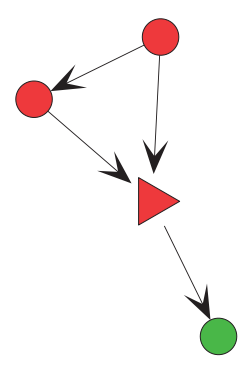

Columbia University scientist

27 actors, 234 ties, 215 transitive triads

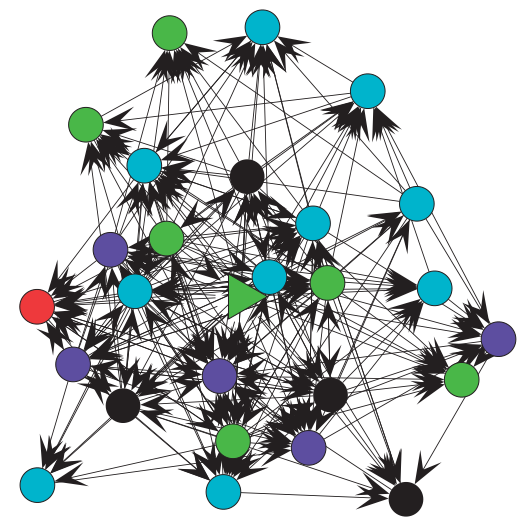

University of Alabama scientist 15 actors, 56 ties, 39 transitive triads

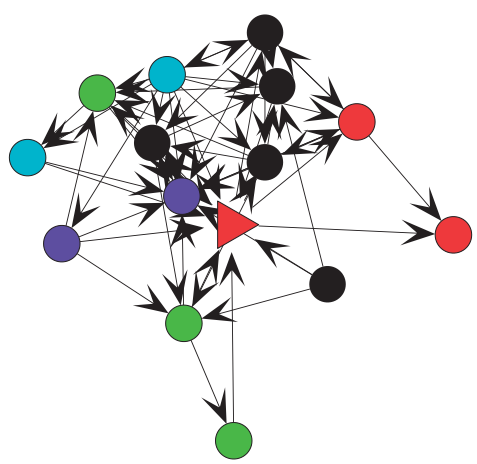

$\triangle$ Ego

Strongly agree

Agree

Neutral

Disagree

Strongly disagree

No response

These errors have been corrected in the online versions of the Article. 